\title{
Composition of $\gamma$-ray induced triethoxyvinylsilane-methyl methacrylate copolymers determined by XPS
}

\author{
Tuncer Çaykaraa ${ }^{a, *}$, Olgun Güven $^{b}$ and Şefik Süzer ${ }^{c}$ \\ a Department of Chemistry, Gazi University 06500 Beşevler, Ankara, Turkey \\ ${ }^{b}$ Department of Chemistry, Hacettepe University 06532 Beytepe, Ankara, Turkey \\ ${ }^{\complement}$ Department of Chemistry, Bilkent University 06533 Ankara, Turkey \\ (Revised 7 November 1997)
}

\begin{abstract}
Methyl methacrylate (MMA) was copolymerized with triethoxyvinylsilane (TEVS) using ${ }^{60} \mathrm{Co}-\gamma$ radiation at varying masses of the liquid monomers in the feed. Their homopolymers PMMA and PTEVS were also prepared by the same method. Thin copolymer and homopolymer blend films were prepared by dissolving the polymers in tetrahydrofuran and casting on clean Teflon or glass substrates. Analysis of the surface composition of these films using XPS indicated that the surfaces of the blend films were completely covered by PTEVS after $10 \%$ composition by weight. Similar analysis on the copolymer films, however, revealed that the surfaces of the copolymers contain comparable amounts of PMMA and PTEVS in agreement with the bulk analysis using infrared spectrometry. Hence, use of PMMA/PTEVS copolymers for stone preservation seems feasible by radiation induced polymerization. (C) 1998 Elsevier Science Ltd. All rights reserved.
\end{abstract}

(Keywords: $\gamma$-rays; triethoxyvinylsilane-methyl methacrylate copolymers; $\mathbf{X}$-ray photoelectron spectroscopy)

\section{Introduction}

Stone is one of the most important structural and monumental materials. Being mainly outdoors, it suffers severely from the degradative action of frost, weathering, attacks of acidic gases and soluble salts carried by air movements. Indoors, attacks by atmospheric pollutants is the main cause of deterioration. Preservation of stone has emerged as an important task for scientists. Polymers are widely used as materials for conservation of archeological artifacts made of stone. The polymeric materials to be used, usually in the form of coatings, should not alter the structure of stone, should impart mechanical stability and be compatible with the substrate material. It is highly improbable for a single polymer to possess all such properties, and hence preparation of copolymers might offer an answer. Organofunctional silanes have been used as coupling agents between inorganic (such as stone) and organic (such as polymers) substrates. The copolymers carrying triethoxyvinylsilane (TEVS)-methyl methacrylate (MMA) units are strong candidates for having promising applications on simultaneous preservation and consolidation of archeological artifacts made of stone. Radiation induced homo- and/or copolymerization is a feasible method of preparation.

In previous studies, we had reported TEVS and MMA copolymers synthesized by radiation induced polymerization techniques ${ }^{1,2}$. In this study, we report on the surface composition of these copolymers and homopolymer blends using the surface sensitive X-ray photoelectron spectroscopic (XPS) technique.

\section{Experimental}

The copolymers were prepared by the well-known ${ }^{60} \mathrm{Co}$ $\gamma$-ray induced polymerization technique at a dose of

\footnotetext{
* To whom correspondence should be addressed
}

$8.5 \mathrm{kGy}$ and at room temperature. Composition variation was enforced by varying the volume of the liquid monomers in the feed. After radiation exposure, the copolymers were dissolved in tetrahydrofuran (THF). Films were prepared by solvent evaporation from $1 \mathrm{wt} \%$ solution followed by casting on clean Teflon or glass substrates. Complete drying was achieved in a vacuum oven at $50^{\circ} \mathrm{C}$. Blends of the polymers were prepared by codissolving the separately PTEVS and PMMA homopolymers and casting.

Surface compositions were determined by XPS, using a Kratos ES300 spectrometer with $\mathrm{MgK}_{\alpha} \mathrm{X}$-rays $(1253.6 \mathrm{eV})$ under a vacuum of ca. $2 \times 10^{-9} \mathrm{mbar}$ at electron take-off angles of $90^{\circ}$ and $30^{\circ}$, corresponding to analysis depths of $10 \mathrm{~nm}$ and $5 \mathrm{~nm}$ respectively ${ }^{3,4}$. An estimate of the bulk composition of the films was obtained by infra-red (i.r.) analysis of the films prepared on $\mathrm{NaCl}$ discs by deposition from their THF solutions and after evaporating the solvent.

\section{Result and discussion}

Homopolymer blends. It is well-known that the surfaces of polymers containing silicon are always enriched with respect to silicon containing component due to the low surface energy of the latter. Figure 1 depicts the XPS spectra of PMMA and PTEVS as well as blends of them at 5\% and $15 \%$ (by weight) compositions recorded at $90^{\circ}$ electron take-off angle. The XPS spectrum of PMMA consist of a single but broad $\mathrm{O} 1 \mathrm{~s}$ peak and a multiple character $\mathrm{C} 1 \mathrm{~s}$ region. The $\mathrm{C} 1 \mathrm{~s}$ region can be curve-fitted to an esteric component at $288.9 \mathrm{eV}$ a methoxy one at $286.7 \mathrm{eV}$ and a hydrocarbon peak at $285.0 \mathrm{eV}$ with their expected stoichiometric ratios in close resemblance to the compiled reference spectrum $^{3}$. The broad Ols peak can be curve-fitted to two components. The spectrum of PTEVS has a sharp O1s, a double $\mathrm{C} 1 \mathrm{~s}$ and single $\mathrm{Si} 2 \mathrm{p}$ peaks again with their stoichiometric ratios ${ }^{3,5}$. Table 1 contains the relevant data. The corresponding spectra of the $5 \%$ and $15 \%$ blends are very similar to that of PTEVS except in the $5 \%$ case the esteric 
Table 1 Binding energy and composition derived from XPS

\begin{tabular}{|c|c|c|c|}
\hline \multicolumn{4}{|c|}{ Cls } \\
\hline & $\mathrm{C}-\mathrm{H}$ & $(C)$ & $c=0$ \\
\hline PMMA & $\begin{array}{l}285.0 \\
(0.71)\end{array}$ & $\begin{array}{l}286.7 \\
(0.14)\end{array}$ & $\begin{array}{l}288.9 \\
(0.15)\end{array}$ \\
\hline PTEVS & $\begin{array}{l}284.6 \\
(0.56)\end{array}$ & $\begin{array}{l}286.5 \\
10.441\end{array}$ & \\
\hline
\end{tabular}

"Binding energies in $\mathrm{eV}$ and intensities in parenthesis

"Corrected for transmission function and photoemission crosu-section"

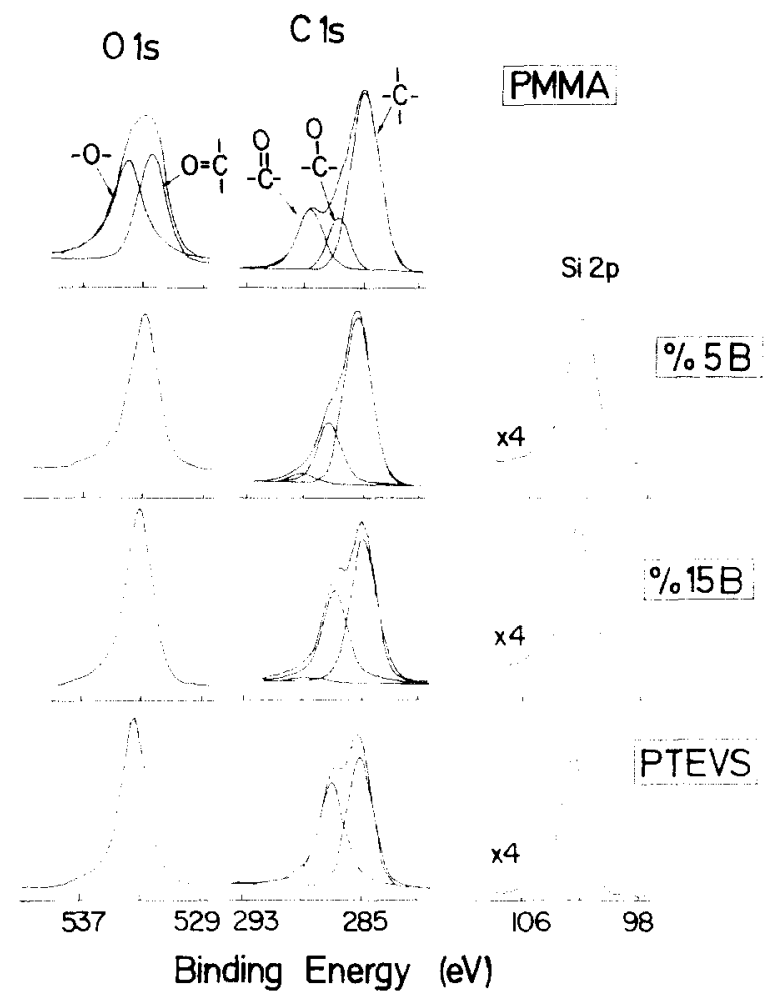

Figure 1 Parts of the XPS spectra of films of PMMA. PTEVS and blends containing $5 \%$ and $15 \%$ PTEVS

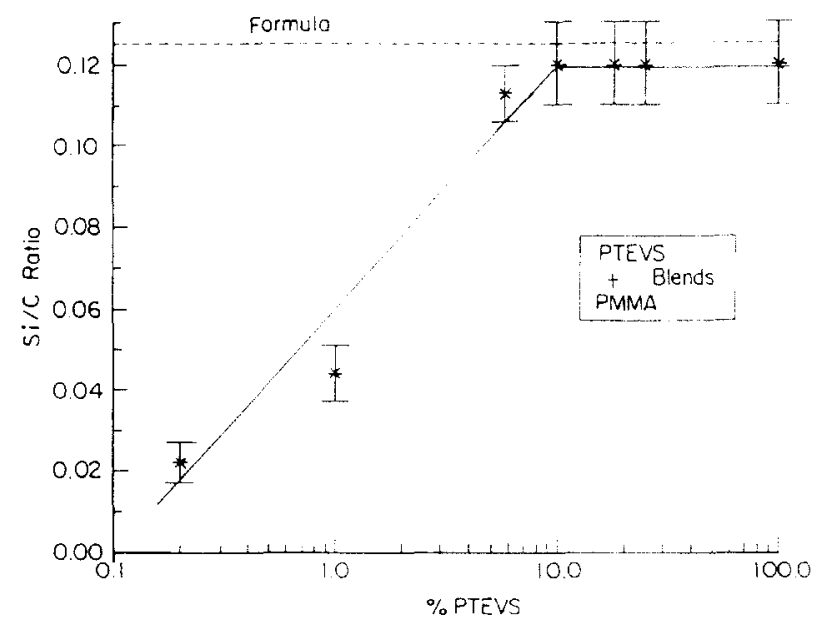

Figure 2 XPS derived Si/C ratio of various blends against the percentage PTEVS composition (by weight). The stoichiometric ratio of 0.125 (i.e. $1 \mathrm{Si}$ atom $/ 8 \mathrm{C}$ atom) is achieved after $10 \%$

component in the $\mathrm{C} 1 \mathrm{~s}$ region can be recognized. The spectra recorded at $30^{\circ}$ electron take-off angle $\mathrm{Si}$ peaks are even stronger; indicating further the surface enrichment of Si. After correction for the transmission function of the

\begin{tabular}{|c|c|c|c|}
\hline 01 & & $S i 2 p$ & $\mathrm{Si} / \mathrm{C}^{\prime \prime}$ \\
\hline 06 & $O=C$ & & Atomic ratio \\
\hline $\begin{array}{l}532,3 \\
10.211\end{array}$ & $\begin{array}{l}533.6 \\
(0.23)\end{array}$ & - & $\ldots$ \\
\hline $\begin{array}{l}53.0 \\
10>9,1\end{array}$ & - & $\begin{array}{l}101.9 \\
(0.16)\end{array}$ & 0.12 \\
\hline
\end{tabular}

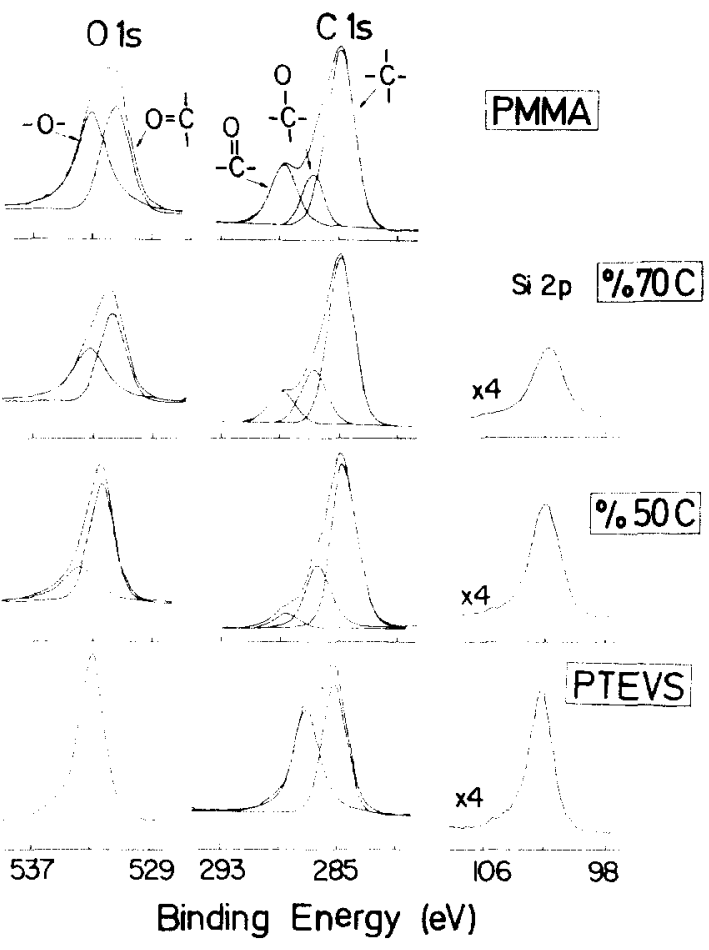

Figure 3 XPS spectrat of PMMA, PTEVS and two copolymers. $70 \%$ and 50\% $($ refer to $70 / 30$ and $50 / 50$ mass ratios of TEVS/MMA monomers in the feed

spectrometer and the X-ray photoemission cross-sections ${ }^{3}$ surface compositions of the films can be obtained from the XPS spectra as Si/C atomic ratio as functions of the percentage composition, which are plotted in Figure 2. Since the surface tension of PTEVS, $33.4 \mathrm{dyn}^{-1}$. is lower than that of PMMA, $41.1 \mathrm{dyn}^{-16}$, the surface is completely dominated by PTEVS after $10 \%$ composition. Previous studies have shown that these blends are all heterogeneous with visible phase separation occurring over most of the compositional range ${ }^{2}$. Similar surface enrichment of silicon was reported by Kawakami et al. by XPS measurements of methyl methacrylate-polysiloxane graft copolymers blended with PMMA ${ }^{7}$.

Copolymers. Since the reactivity of MMA towards ${ }^{6()} \mathrm{Co}$ $\gamma$-ray induced polymerization was much higher when compared to that of TEVS, and considering the differences in molecular weight of the monomers we had to vary the TEVS composition in the feed between $30-90 \%$ by weight in order to obtain appreciable $\mathrm{Si}$ concentration (as evidenced by XPS) in copolymer films. Figure 3 depicts the XPS spectra of the copolymer films at two different initial monomer concentration ratios in the feed. Spectra are similar in appearance, however, the relative intensities are drastically different from those of the blends. Two points are noteworthy. First, the surface compotion is no longer dominated 


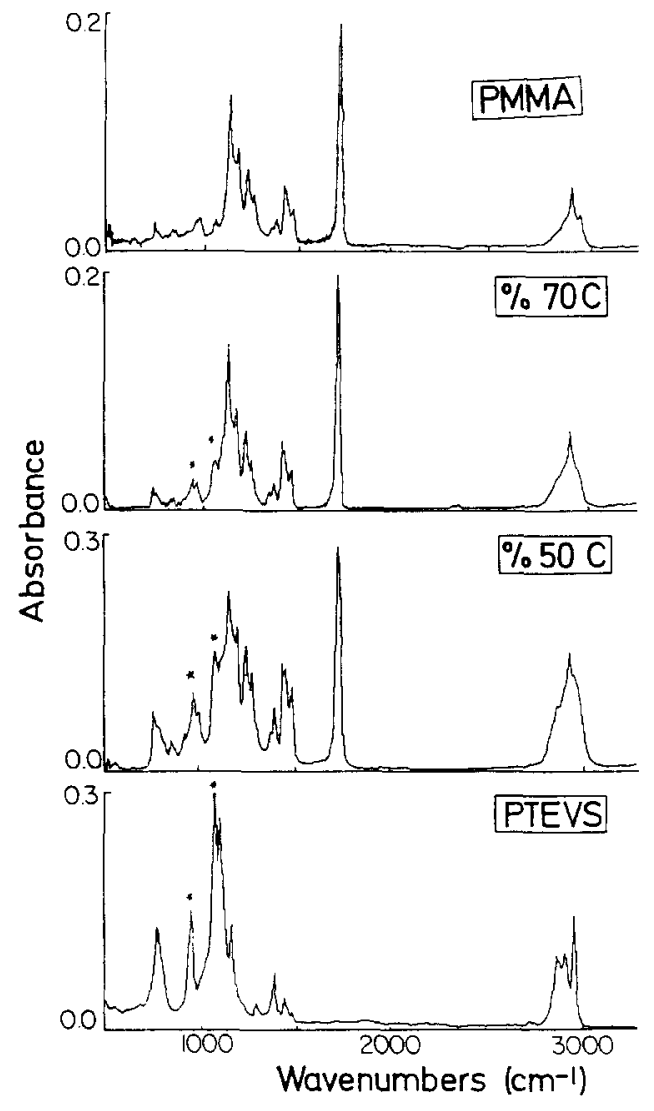

Figure 4 I.r. spectra of PMMA, PTEVS and two copolymers prepared on $\mathrm{NaCl}$ discs deposited from their solutions in $\mathrm{THF}$ and after solvent evaporation

by $\mathrm{Si}$ even as high as $90 \%$ TEVS concentration in the feed. Secondly, contrary to expectations, $\mathrm{Si}$ composition decreases slightly as the percentage TEVS composition in the feed increases (this is also evident from the figure that the $\mathrm{Si} 2 \mathrm{p}$ peak in the spectrum of the $\% 70$ copolymer films is weaker than that of $\% 50$ copolymer film). To determine whether or not these are due to surface effects, i.r. absorption spectra (Figure 4) are recorded by preparing films on $\mathrm{NaCl}$ discs from deposition of their solutions in THF and after evaporation of the solvent. Care was taken to prepare the films such that the maximum absorption to be less than 0.5 absorbance. The i.r. spectra of PMMA and the copolymers are dominated by the carbonyl band at around $1700 \mathrm{~cm}^{-1}$, and $\mathrm{C}-\mathrm{H}$ bands around $2900 \mathrm{~cm}^{-1}$, whereas in the spectrum of PTEVS $\mathrm{Si}-\mathrm{O}$ bands around $100 \mathrm{~cm}^{-1}$
Table 2 Composition derived from XPS and i.r. analysis of $\gamma$-ray induced MMA and TEVS copolymers (composition of $15 \%$ blend films is also included for comparision)

\begin{tabular}{lcc}
\hline \% TEVS in the feed & $\mathrm{Si} / \mathrm{C}$ & $\begin{array}{l}\mathrm{CH} / \mathrm{CO} \text { band ratio } \\
\text { (i.r.) }\end{array}$ \\
\hline 0 (PMMA) & - & 0.8 \\
50 & 0.06 & 1.4 \\
70 & 0.05 & 1.2 \\
100 (PTEVS) & 0.12 & $x$ \\
$15 \%$ Blend & 0.12 & 1.7 \\
\hline
\end{tabular}

are dominant. An estimate of the bulk composition can be obtained from the ratio of the integrated intensities of the $\mathrm{CH}$ and $\mathrm{CO}$ bands. Table 2 gives these values for the various copolymers as well as those derived from XPS measurements. The ratio of the integrated $\mathrm{CH} / \mathrm{CO}$ band is 0.8 in PMMA whereas they are 1.4 and 1.2 in the $50 \%$ and $70 \%$ copolymers respectively; in total agreement with the XPS results (XPS spectra recorded at $30^{\circ}$ electron take-off angle are not very different from those recorded at $90^{\circ}$, revealing again the fact that no surface enrichment is observable in copolymers). Hence, in complete contrast to the blends case, the copolymers contain comparable amounts of PMMA and PTEVS, both in their bulk as well as their surfaces which completely satisfies the the expectations of the present study. The aforementioned slight anomaly in the composition derived with respect to the percentage composition in the feed is real and reproducible. This must be related to the complex kinetics of the ${ }^{60} \mathrm{Co} \gamma$-ray induced polymerization of these two monomers, but falls outside the scope of our objectives.

\section{References}

1. Çaykara, T., Eroğlu, M. S. and Güven, O., J. Appl. Polvm. Sci. (submitted).

2. Çaykara, T., Tan, E. and Güven, O., J. Appl. Polym. Sci. (submitted).

3. Briggs, D. and Seah, M., Practical Surface Analysis. Volume I: Auger and X-Ray Photoelectron Spectroscopy. Wiley, Chichester, 1990.

4. Chen, X., Gardella, J. A. Jr, Ho, T. and Wynne, K. J., Macromole cules, 1995, 28, 1635.

5. Beamson, G. and Briggs, D., High Resoltution XPS of Organic Polymers. Wiley, New York, 1992.

6. Brandrup, J. and Immergut, E. H., eds., Polymer Handbook. John Wiley, New York, 1989

7. Kawakami, Y. and Yamashita, Y., in Ring-Opening Polymerization, Ch. 19, ed. J. E. McGrath. American Chemical Society, Washington D.C., 1985. 